\title{
中国传统文化在英语文学专业课程教学中的实践与思考一一 “美国文学导论”课程为例
}

\author{
吴雨宁
}

长春师范大学

DOI:10.32629/er.v2i12.2216

[摘 要] 在新 “国标” 的导向下,各高校英语专业在原有的人才培养目标 “掌握英语语言文学的知识与技能, 了解英语国家社会与文化” 的基 础上, 不断融入中国特色和本土文化, 致力于培养具备中国情怀和能够传播中华文明的新型英语专业人才。因此, 英美文学的课程教学也必须改 变传统教学内容和模式,将优秀的中国传统文学引入到英语文学的教学实践中。本文先分析了此举的必要性,并以文学方向主干课程中的 “美国 文学导论” 为例, 分别从实践方法和实现效果与反思两个方面, 探究如何在具体的文学教学实践中构建起中外文化互通的桥梁, 实现 “外国文化 引进来”与 “中国文化走出去”的双向同步发展。

[关键词] 中国传统文化; 英语文学课程; 美国文学导论; 教学实践

在新颁发的《高等学校英语专业本科教学质量国家标准》中, 对英语 专业人才提出了新要求, 除了需要具备扎实的语音、词汇、语法、语篇和 语用等基本语言知识技能和厚实的语言、文学、文化相关专业知识外, 还 要求学生具有中国情怀与国际视野, 了解中国传统文化, 并肩负起传播中 华文明的伟大使命。从此次目标转向可以看出, 传统的外语人才培养模式 已无法顺应新的时代要求, 必须要在英语教学过程中融入中国传统文化的 精髓, 增强文化身份认同, 提升文化自信, 让中国文化 “走出去”。因笔者曾 负责英语专业三年级 “美国文学导论” 的教学工作, 遂尝试结合自身实际 教学经验以这门课程为例, 对英语文学方向的课程中的中外文化渗透和交 流, 提出一点自己的思考。

\section{1 在英美文学课程中融入中国传统文化的目的}

英美文学课程在普通高等院校的英语语言文学专业课程体系中属于 专业方向课, 一方面在知识层面上, 要求学生按照一定的标准对主要文学 体裁的形式(包括诗歌、小说、戏剧等)进行分析、认识和评价。能够梳理 文学各个要素, 对批评方法进行概括总结, 并应用于批评实践中。还要掌握 鉴赏、分析文学作品的必要技巧, 对文学作品和文学运动进行分析, 逐步培 养自身的文学鉴赏和反思能力。另一方面, 作为 “人文教育的重要组成部 分”, 英美文学的教学中所体现的 “人文精神” 要求学生对英语作家及其 文化背景有所了解, 并能理解不同文化内涵, 尊重各个文化之间的差异, 能 够通过文学学习延伸至对人学的思考, “增强人文素质, 成为适合新时代要 求的人文主义者” (郭剑英2017)。

英语课文学习是学生在学习过程中积累语言素材的重要途径, 但仅仅 依靠课文上的内容是远远不够的, 因此在学生搞好课堂教学的基础上, 教 师还要要求学生去增加阅读材料, 补充自己的阅读知识面, 英语课外阅读 是将学生在课堂上所学知识再加以巩固的过程, 也是学生作为教材阅读教 学的延伸。教师要重视学生课外阅读的学习, 这对于补充知识有很多的促 进作用, 需要教师注意的是, 在选择材料的时候, 要遵循因材施教的原则, 给予班级里的优等生和后进生难度适当的阅读材料, 促进各个阶段的学生 得到有效提升。学生经过大量的阅读练习, 能够更加独立的掌握阅读技巧, 学生的词汇量在不断练习中得到提升, 有利于提高学生的独立阅读能力, 培养学生的发散思维, 增强学生对阅读的信心。

\section{5 结束语}

综上所述, 阅读教学贯穿课堂内外, 我们教师要积极培养学生阅读的
那么, 在培养学生人文精神的过程中, 英美文学课程教学则一直徘徊 在自身的人文困境之中: 在了解外来文明吸收西方文化时应保持怎样的距 离和尺度? 如何处理文学作品中涉及到的一些较为敏感的政治性问 题? 作为授课教师, 在带领学生进行文化思辨时应处于什么样的立场, 扮演怎样的角色? 所幸的是, 新 “国标” 为我们回答这些问题明确了新 方向, 提供了新思路, 中国传统文化可以成为引领我们走出自身困境的 指南针和方向标。通过挖掘中国传统文学中独特的思想精髓, 在提高学 生学习英美文学兴趣、吸收西方文化的同时, 启发他们用跨文化的角度 去反省本土文化, 也能站在本土文化的立场去思考和评判外来文化, 使 其兼具中国情怀和世界视野, 从而形成真正的思辨精神, 成为合格的人 文主义者。由此可见, 讲中国传统文化引进英美文学课程十分具有前瞻 性和必要性。

\section{2 中国传统文化在 “美国文学导论” 课程中的教学实践}

“美国文学导论”是针对英语专业大三学生开设的文学方向主干课程, 要求学生了解美国文学各个时期的文学流派, 代表作家作品与其相应的文 学特征。该课程通常开设于第6学期, 学生已经具备一定的英语语言基础知 识和相对较高的学习意识与能力, 并且通过对第 5 学期开设的 “英国文学导 论”的学习, 学生也对基本的文学体裁和相关术语具有一定的了解, 掌握了 一些分析鉴赏作品的方法和原则。

考虑到上述学情和课程特点, 该课程在文本选择, 课程实施与考核模 式上将中国元素贯穿始终, 使学生在跨文化的比较学习中思考本土文学与 
美国文学的共性与差异, 求同存异, 相互理解, 在学习中增强民族文化自信, 也为学生传播中国传统文学与文化, 实现文化输出和交流, 提供了的新视 角和新方法。“美国意象主义诗歌” 为 “ 20 世纪美国文学” 章节中的一个 小节, 授课安排为 2 课时, 下面笔者将以此为案例, 简要阐释对中国传统文 化的学习是如何在具体的英美文学教学实践环节应用展开的。

首先, 在文本选择上, 笔者之所以从本节涵盖的意象派诗歌重要代 表人物中选择了埃兹拉 ・庞德 (EzraPound) 作为重点研读诗人, 除了考虑 到其在意象派运动中的重要地位, 还与庞德在中国古典诗歌的深厚造诣 以及他为东西方诗歌互相借鉴所做出的卓越贡献休息相关。因此在课前, 将 “庞德与他的中国情结” 在线微课视频和相关测试上传至 “超星学习 通” 移动教学终端中的虚拟班级资源包里, 并跟踪监测学习进程, 确保自 主预习质量。

其次, 在授课环节中, 先以著名翻译家许渊冲翻译的元曲作家马致 远的《天净沙 - 秋思》英文译诗作为导入, 在欣赏与比较中英各异的诗 歌语言时, 启发学生发现其中蕴藏的意象 (image), 引出本课的核心内容, 带领学生对学习通中关于庞德的个人生平和写作特点进行复习和适当 补充, 再借助 $f 1$ ash动画和多媒体技术, 对美国意象派诗歌的特点进行分 类总结并对庞德的名篇 “在地铁站” (InaStationof theMetro) 做了细致 的文本分析。

最后, 在考核方面, 因本课程采取形成性评价和终成性评价相结合的 考核模式, 所以平时的课后任务也作为成绩的重要参考依据。就本次课而 言, 学生需要根据 “学习通” 中的随机分配的分组任务, 结合课上对两首中 英意象诗歌的解读, 从不同方面比较中国传统文学中的元曲与美国意象诗 歌, 最后并以小组形式在英语角面向全校中外学生进行汇报演讲, 借由美 国文学向外国学生展示中国古典文学的魅力。

\section{3 中国传统文化在 “美国文学导论” 课程中的引入效果与反思}

笔者结合学生的在线测评结果, 课堂小组讨论, 英语角汇报演讲, 期末 试卷分析, 以及学生评课结果等多方反馈情况, 对中国传统文化在该课程 的引入效果进行了较为全面的分析。认为大体上还是初步实现了的本门课 的教学目标, 通过线上线下同步学习, 教师授课和自主学习相结合的学习 模式, 使学生在学习美国文学经典的同时, 加深了对本土文学的理解, 增强 了跨文化交际的意识, 并能主动传承优秀中华文化, 提高了将中国视角带 向世界的民族认同感和文化自信心。

但是经过对这一学期的教学实践的反思, 笔者也发现了将中国文化纳
入英语文学课程中的一些问题, 而且这些问题可能也存在于其他国别文学 的课程教学中。其中最为明显的仍是学生在建立两种语言文学之间的关联 时所遇到的理解困难和共情障碍。其实中国传统文学的引入对于英语文学 学习者而言是一把双刃剑, 一方面, 有了熟悉的母语加持, 学生可以讯速地 对目标语言产生积极的正向迁移, 加深对其的理解。另一方面, 但是文学不 仅仅是一种语言形式, 具备单一的表意功能; 它更是一种语言艺术, 承载着 独特的意蕴和美感。而以不同的语言系统所书写的文学之间, 往往存在着 大面积难以通过翻译填补的理解空白, 想要实现意蕴与美感的完整传输更 是难上加难。因此, 在进行中英文学对比鉴赏初期, 一些学生, 尤其是语文 和英语基础都不是很强, 语言感知能力也相对较弱的学生, 会感到匪夷所 思, 尽管很努力, 但仍然无法构建起两种文学语言之间的通感, 甚至会渐渐 出现排斥情绪。这就需要授课教师在课堂活动和讨论题的设置上循序渐进, 耐心引导。

\section{4 结束语}

综上所述, 将中国传统文化的引入高校英语专业教学, 是国家面临 “中 国文化失语” 现象日益严重的情况下作出的及时举措, 也是立足于本民族优 秀文化, 培养顺应国情, 满足时代需求的新型英语人才的必经之路。为课程 和教学改革指明了方向, 为英语文学方向课程注入了新的生机与活力。在距 离修订版 “国标” 颁发不足五年的时间内, 各个高校已然纷纷作出调整和 改变, 也达到了一定的预期效果。虽然仍面临一些问题待解决, 但未来在英 语专业人才培养方面, 实现 “外国文化引进来” 与 “中国文化走出去” 的 双向同步发展, 还是指日可待的。

\section{[参考文献]}

[1]郭剑英. “外国文学经典”教学中,我们应该持有怎样的立场? 以美国教学为例 [J].外文研究,2017,(5):42-45.

[2]高等学校外语专业教学指导委员会英语组.高等学校英语专业英 语教学大纲 $[M]$. 北京/上海: 外语教学与研究出版社/上海外语教育出版 社,2000:37-39.

[3]张良红,余军.高校英语专业美国文学课程设置与教学的反思 [J].南 通大学学报(教育科学版),2010,26(01):93-96.

\section{作者简介：}

吴雨宁 $(1992--)$, 女, 汉族, 吉林人, 长春师范大学外国语学院英语 教师,助教,硕士研究生,研究方向：英国及爱尔兰小说。 